\title{
Simulation of wheat ontogenesis. I. Appearance of main stem leaves in the field
}

\author{
F. Miglietta \\ I.A.T.A - CNR, Institute of Environmental Analysis and Remote Sensing for Agriculture, P.le delle Cascine 18, I-50144 \\ Florence, Italy
}

\begin{abstract}
Rate of leaf appearance differs among wheat crops sown in the field at different dates. This can be interpreted either as a direct effect of the date of sowing on the rate of leaf appearance or as an indirect effect of an ontogenetic decline in the rate of appearance. Analysis of data from both laboratory and field experiments led to the conclusion that the second hypothesis is more reliable. A simulation model of leaf appearance was formulated on the basis of this hypothesis, and tested using experimental results from the literature and 2 original experiments carried out in Italy. There was a good agreement between experimental data and simulation results. The discussed model simplifies the problem of the simulation of leaf appearance. Other models are based on a complicated relation between the rate of change in daylength at crop emergence and the rate of leaf appearance, which does not have a physiological base.
\end{abstract}

\section{INTRODUCTION}

Leaf appearance, in wheat, is the result of 2 distinct processes: leaf primordia initiation and extension. When optimal growth conditions occur, both are controlled mainly by temperature. In a previous paper (Miglietta 1989), the final number of initiated vegetative primordia was shown to be proportional to the time that elapsed between sowing and the occurrence of double ridges. It was concluded that leaf primordia initiation is independent of daylength.

The rate of leaf appearance is similarly expected to be independent, but a difference in the rate of leaf appearance is always observed when this is measured at the same time in crops sown at different dates. It is observed that leaves of crops sown later appear faster.

Such behaviour can be explained either as a direct effect of the date of sowing on the rate of leaf appearance, that makes later-sown crops have higher leaf appearance rates (Hypothesis 1), or as an indirect effect of an ontogenetic decline in the rate of leaf appearance as the plant ages (Hypothesis 2). According to this second hypothesis, the time taken by each leaf primordium to extend from the apex to the point of emergence increases for each subsequent leaf, leading to a decline in the rate of appearance of subsequent main stem leaves.
Hypothesis 1 is commonly accepted because main stem leaves were observed to appear at approximately constant rates when plants were grown under constant conditions (Malvoisin 1984).

The aim of this paper is to propose a model for the evaluation of leaf appearance in wheat. For this purpose some experimental observations from the literature were analyzed and interpreted by means of both Hypothesis 1 and Hypothesis 2 and the leaf appearance process was reconsidered. Hypothesis 2 is concluded to be the more realistic, and the leaf appearance model is developed on this basis. The model is tested by means of both original and published field experiment data

\section{MODEL DEVELOPMENT}

Kirby et al. (1985) sowed Norman winter wheat in the field at Cambridge, England (Latitude $52^{\circ} 11^{\prime} \mathrm{N}$ ), on 4 dates during the season 1980-81. Leaf appearance measurements of different sowings overlapped for certain periods so that it is possible to compare the leaf appearance rates of different crops. Linear regression analysis of the number of leaves on time (in days) for monthly periods of overlapping leaf production was performed for September and October 
sowings, in order to show the different monthly averages of daily leaf appearance rate. The numbers of days elapsing between the appearance of subsequent leaves, i.e. the phyllochrones estimated as the reciprocal of observed rates, were calculated. These data are shown in Table 1, where the corresponding number of emerged main stem leaves over time is also given.

As expected, the phyllochrones appear to be shorter in the later sowing. The difference between the 2 sowings can be interpreted by means of both Hypothesis 1 and 2: in the first case, the mean difference of about $11 \%$ between the phyllochrones of the 2 sowing dates is understood to be a direct effect of the date of sowing on the rate of leaf appearance; in the second case this is done by assuming that each phyllochrone is about $2 \%$ longer than its predecessor.

Any direct effect of the date of sowing on the rate of leaf appearance must be a function of the different photoperiod experienced by the crops at the time of emergence; however it has already been demonstrated that the daylength does not directly affect the rate of leaf initiation, and no other physiologically based hypotheses have been made to date to explain this dependence (Kirby \& Perry 1987).

On the other hand, Hypothesis 2 provides a satisfactory explanation of the field observation simply by assuming that subsequent phyllochrones, in wheat, are not constant in a constant temperature but that they increase slightly as the plant ages. An increase of about $2 \%$ for each subsequent phyllochrone amounts to $12 \mathrm{~h}$ difference between phyllochrones for an initial phyllochrone of $25 \mathrm{~d}$ and to about $2 \mathrm{~h}$ for an initial phyllochrone of $4 \mathrm{~d}$. This increase is so small that it can easily escape direct detection even in controlled-environment experiments and does not bring Hypothesis 2 into conflict with the common observation of approximately constant phyllochrones in plants grown under constant conditions.

On the basis of this hypothesis a model for determining the number of leaves $(L)$ can now be formulated. In the model, the number of initiated primordia $(P)$ is calculated as the sum of daily rates of initiation which are a linear function of air temperature (Miglietta 1989) according to:

$$
\frac{\mathrm{d} P}{\mathrm{~d} t}=-0.038+0.0149 T \quad \text { for } T>2.55
$$

where $T=$ air temperature $\left({ }^{\circ} \mathrm{C}\right) ; \mathrm{d} P / \mathrm{d} t=$ the initiation rate of vegetative primordia.

It is then assumed that the rate of leaf appearance is equal to the initiation rate of vegetative primordia minus a term depending on the number of emerged leaves according to:

$$
\frac{\mathrm{d} L}{\mathrm{~d} t}=\frac{\mathrm{d} P}{\mathrm{~d} t}(1-a L)
$$

and, finally, the potential number of emerged leaves is calculated by solving analytically Eq. (2):

$$
L=\frac{1-\exp \left[-a\left(P-P_{o}\right)\right]}{a}
$$

where $P_{0}=$ the number of primordia already initiated at the apex at the time of crop emergence.

The parameter ' $a$ ' of Eqs. (2) and (3) is expected not to be too far from the percentage increase in phyllochrone time measured by Kirby et al. (1985) in the field. It can be calculated by fitting Eq. (4) to the data of the relationship between $L$ and $P$ measured at any given time of the growing period until the occurrence of double ridges.

Curve fitting was done by means of the modified Newton's method of non-linear fitting (Ross 1975) and the estimated value of the parameter a appears to be very close to the field observation made by Kirby et al. (1985) $(a=0.03)$.

The relationship between $L$ and $P$ is illustrated in Fig. 1 where the points denote experimental observations found in the literature for several wheat varieties grown in different climates, and the line $\mathrm{B}$ represents the fitted curve. If the rate of primordia initiation and the rate of leaf appearance were the same, the relationship between $L$ and $P$ should follow the simple relationship:

$$
L=P-4
$$

Table 1. Monthly average of daily leaf appearance rates ( $L r_{;}$leaves $\mathrm{d}^{-1}$ ) and the corresponding phyllochrones ( $P h$; d), as measured in the field for September (1) and October (2) sowings (data from Kirby et al. 1985). Numbers of emerged main stem leaves ( $N$ ) in each sowing are also reported

\begin{tabular}{lcccccc|}
\hline Month & $L r_{1}$ & $L r_{2}$ & $P h_{1}$ & $P h_{2}$ & $N_{1}$ & $N_{2}$ \\
\hline November & 0.068 & 0.074 & 14.7 & 13.4 & 6.0 & 1.4 \\
December & 0.040 & 0.038 & 25.0 & 26.5 & 7.4 & 2.6 \\
January & 0.035 & 0.049 & 28.1 & 20.5 & 9.5 & 4.0 \\
February & 0.047 & 0.049 & 21.4 & 20.5 & 1.8 & 7.5 \\
March & 0.064 & 0.067 & 15.5 & 15.0 & 1.6 & 7.4 \\
\hline
\end{tabular}


because the number of vegetative primordia that are already initiated when the crop energes is about 4 (Miglietta 1989). The line A in Fig. 1 represents the linear relationship of Eq. (4), but the observational points markedly diverge from that line, indicating, in accordance with Hypothesis 2, that phyllochrones are longer than the corresponding plastochrones (the time elapsing between the initiation of 2 subsequent leaf primordia) and that this difference tends to increase as the plant ages.

Each leaf primordium has to extend, after initiation, to a given length before it can emerge from the sheat of the previous leaf, and the distance it has to cover from the shoot apex up to that point increases for each subsequent leaf (Gallagher 1979).

It is concluded that there are good morphogenetic arguments for accepting Hypothesis 2: this is in agreement with field observations and it is not rejected by laboratory experiment data. Pending further experimental confirmation, the model has been tested by means of field experiment data from the literature and by data obtained from 2 independent experiments in Italy.

\section{MATERIAL AND METHODS}

A first experiment (Expt 1) was carried out in the field at the experimental farm of Florence University ( $43^{\circ} 55^{\prime} \mathrm{N}$ latitude). A winter wheat ('Maris Huntsman') and a durum variety ('Creso') were sown on 2 dates. The first sowing was on 12 November 1986, and the second on 5 February 1987, both with $10 \mathrm{~cm}$ row spacing, on plots of $1000 \mathrm{~m}^{2}$ each.

After crop emergence, 25 randomly chosen plants were harvested on each plot every 3 or $4 \mathrm{~d}$. Leaf development was estimated by averaging Haun stage

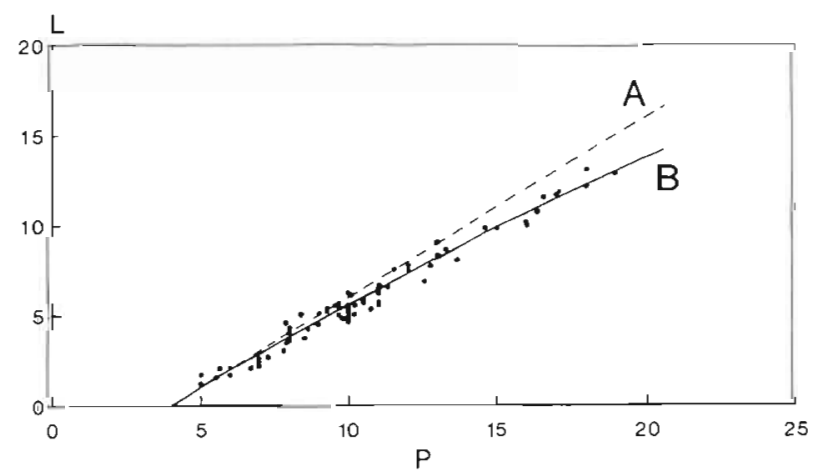

Fig. 1. Relationship between the number of emerged leaves $(L)$ and the total number of initiated vegetative primordia (P). Data from Williams \& Williams (1968), Aitken (1971), Syme (1974), Baker \& Callagher (1983), Thomson (1985) and Miglietta (unpubl.) for a total of 40 wheat cultivars. The dashed line $\mathrm{A}$ indicates the linear relationship of Eq. (4) and the continuous line $B$ presents fitted values of the non-linear relation given in Eqs. (2) and (3) measurements (Haun 1973) made on a sample of 10 plants. Modal plants in the sample were then used for apex observation (Kirby \& Appleyard 1986) and primordia counts (Miglietta 1989) and the remaining plants for leaf size measurement, leaf area estimation and tillers count. A non-destructive sample, of 25 plants per plot, was also used to estimate the final main stem leaf number (Kirby \& Appleyard 1986).

Dry and wet bulb air temperatures, soil temperature profiles, global radiation and wind speed and direction were recorded every $30 \mathrm{~min}$, and averaged daily, throughout the season, using mobile meteorological equipment (Benincasa et al. 1984).

In a second experiment (Expt 2), winter wheat plants, 'Maris Huntsman' variety, were grown in the open at Florence University, which is located $1 \mathrm{~km}$ north of the experimental farm, from 6 August 1987, in 8 large pots (50 cm length, $30 \mathrm{~cm}$ width and $40 \mathrm{~cm}$ depth), in a mixed soil (sand + organic). Two rows were sown in each pot, irrigation was automatically provided twice a day, and a nutrient solution was added weekly to the irrigation water in order to promote optimal growth. Air temperature was recorded every $30 \mathrm{~min}$, and averaged daily. Leaf stage measurements (Haun 1973) were made every $3 \mathrm{~d}$ on 24 plants that were not harvested, and every 3 or 4 on 24 plants that were harvested for apex observation (Kirby \& Appleyard 1986) and primordia counts (Miglietta 1989).

In addition to these 2 experiments, experimental results from the literature were used to validate the model. Sources of these experiments are summarized in Table 2. Where daily temperatures were not available to calculate the rate of primordia initiation, they were randomly generated from decadic means.

The wheat apex remains below ground until the stem starts to elongate, and is exposed to soil temperature rather than air temperature (Hay \& Tuncliffe Wilson 1982). Daily means of soil and air temperatures normally have different amplitudes, but their difference is reduced during the cold period of winter. Calculations of the rate of leaf appearance made for data from Expt 1 using of soil surface or air mean temperatures suggested that this difference can be neglected as a first approximation.

\section{RESULTS}

The comparison between simulation results and the observations made in the experiments listed in Table 2 is illustrated in Fig. 2. In spite of the large variation in both sowing dates and latitudes, the agreement between observational points and the calculated lines is excellent over the whole growth period. This confirms Hypothesis 2 together with the estimate of parameter $a$ of Eq. (2). 
Table 2. List of experimental data sources arranged in order of increasing latitude, used for model validation. The table also provides the legend of Fig. 2

\begin{tabular}{|c|c|c|c|c|c|}
\hline Site & Latitude & Sowing date & Variety & Source & Results in: \\
\hline Rutigliano (I) & $40^{\circ} 10^{\prime}$ & 30 Nov 83 & Creso & Miglietta et al. (1987) & Fig. 2F \\
\hline Florence (I) & $43^{\circ} 55^{\prime}$ & $1=12$ Nov 86 & Maris H. & Miglietta (1989) & Fig. $2 \mathrm{~A}$ \\
\hline Florence (I) & $43^{\circ} 55^{\prime}$ & $1=12$ Nov 86 & Creso & Miglietta (1989) & Fig. $2 \mathrm{~B}$ \\
\hline Florence (I) & $43^{\circ} 55^{\prime}$ & $2=5$ Feb 87 & Maris $\mathrm{H}$ & Miglietta (1989) & Fig. 2A \\
\hline Florence (I) & $43^{\circ} 55^{\prime}$ & $2=5 \mathrm{Feb} 87$ & Creso & Miglietta (1989) & Fig. $2 B$ \\
\hline Randwijk (NL) & $51^{\circ} 50^{\prime}$ & 21 Oct 82 & Arminda & Groot (1987) & Fig. 2D \\
\hline Cambridge (UK) & $52^{\circ} 11^{\prime}$ & $1=10$ Sep 80 & Norman & Kirby et al. (1985) & Fig. $2 \mathrm{C}$ \\
\hline Cambridge (UK) & $52^{\circ} 11^{\prime}$ & $2=24$ Oct 80 & Norman & Kirby et al. (1985) & Fig. 2C \\
\hline Cambridge (UK) & $52^{\circ} 11^{\prime}$ & $3=4 \operatorname{Dec} 80$ & Norman & Kirby et al. (1985) & Fig. 2C \\
\hline Cambridge (UK) & $52^{\circ} 11^{\prime}$ & $4=25$ Feb 81 & Norman & Kirby et al. (1985) & Fig. $2 \mathrm{C}$ \\
\hline Lelystad (NL) & $52^{\circ} 30^{\prime}$ & 25 Oct 83 & Arminda & Groot (1987) & Fig. 2E \\
\hline
\end{tabular}
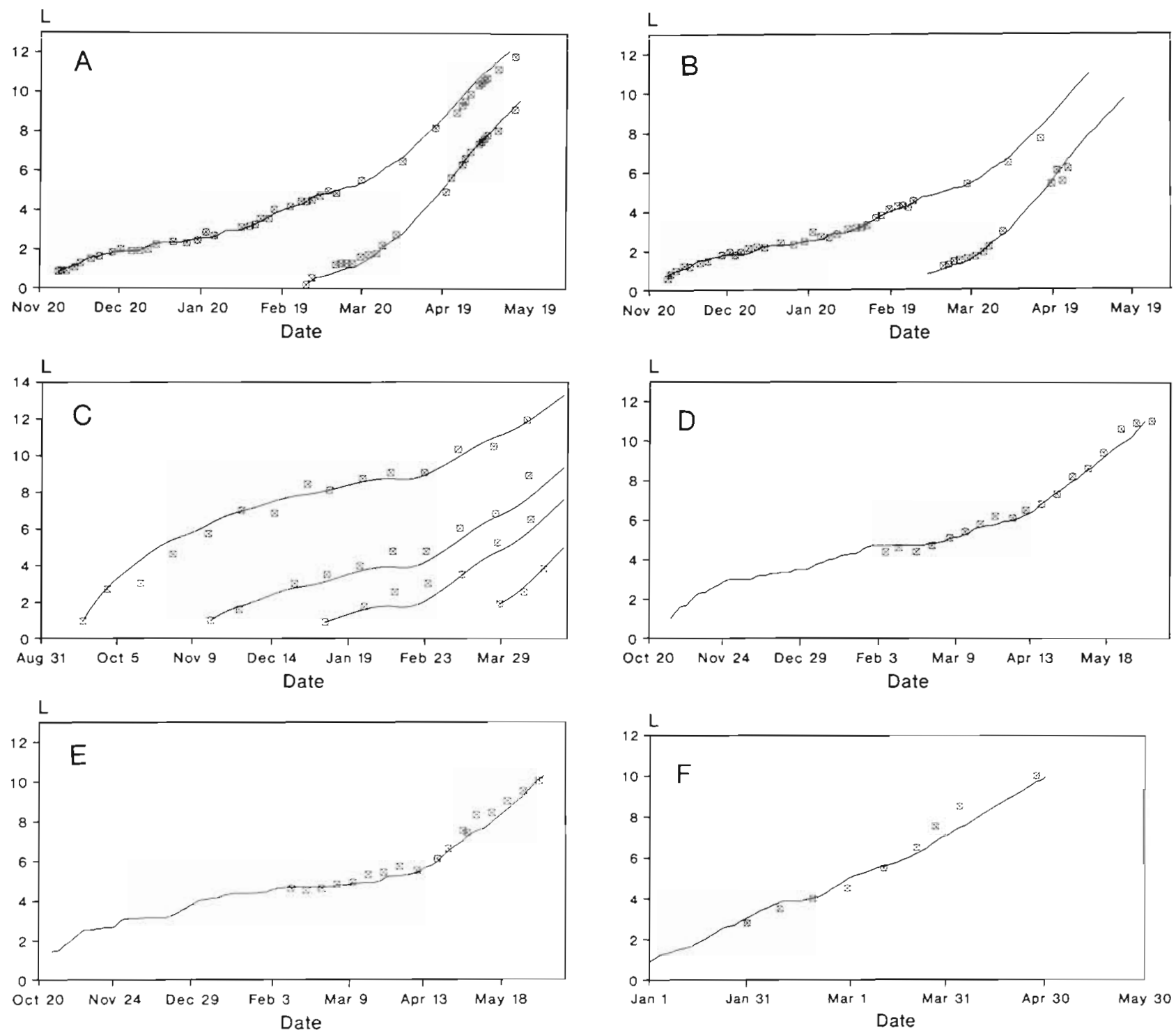

Fig. 2. Simulated (line) and observed (points) number of emerged main stem leaves $(L)$ in field experiments (see Table 2 for experimental details 
Subsequently, data of Expt 2 were used to evaluate model performance under constant high temperatures. In this experiment, average daily temperature remained almost the same, at $18^{\circ} \mathrm{C}$, throughout a period of $32 \mathrm{~d}$, as shown in Fig. 3. Primordia counts showed that leaves were initiated at a constant rate of about 0.23 primordia $\mathrm{d}^{-1}$ and a good estimate of this rate is obtained by means of Eq. (2). The number of main stem leaves that appeared over time is given in Fig. 4 (points) together with the values calculated by means of Eq. (3) (line) and an excellent agreement between observational points and calculation is found. The slight bending of the solid line in the figure is hardly detectable by eye, and this confirms the idea that the decline in leaf appearance rate of subsequent leaves easily escapes direct detection even in controlled experiments.

Results of the comparison between model calculations and experimental observations show that the nonlinearity assumed by Eq. (3) in the relationship between $L$ and $P$ fully explains the differences that are usually found between crops sown at different dates, but does not contradict the common observation of an approximately constant leaf appearance rate at constant temperature. This suggests that the latter observation does not support, by itself, Hypothesis 1.

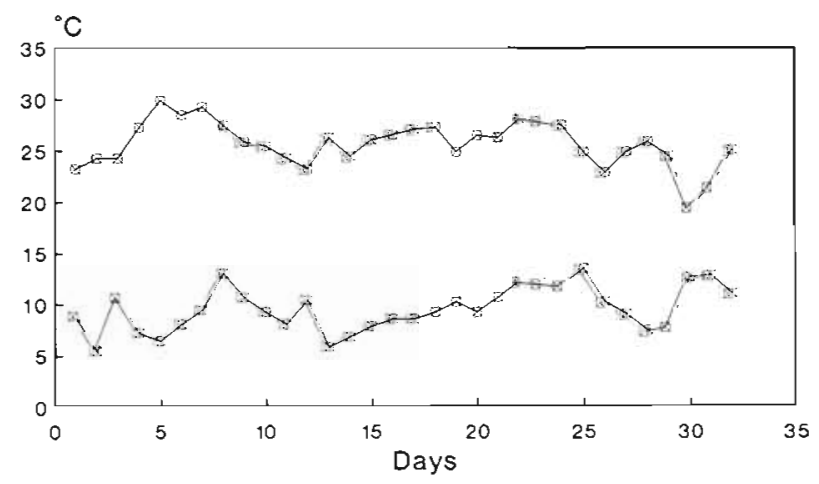

Fig. 3. Mean daily maximum and minimum temperature $\left({ }^{\circ} \mathrm{C}\right)$, measured from plant emergence onward, in Expt 2

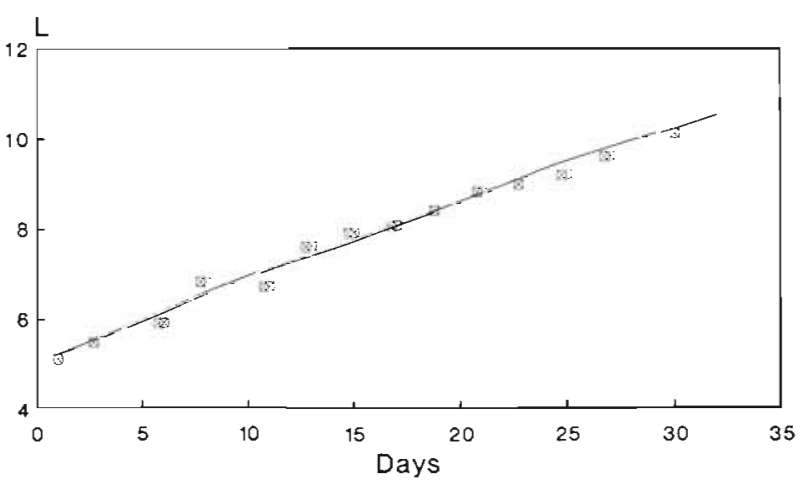

Fig. 4. Observed (points) and calculated (line) number of emerged leaves $(L)$ in Expt 2

\section{DISCUSSION AND CONCLUSIONS}

It was shown that with increasing age of wheat plants, the number of emerged main stem leaves lags further and further behind the number of initiated leaf primordia, so that a small and constant increase in the length of subsequent phyllochrones occurs. This leads to the following conclusions:

- Phyllochrones are longer than corresponding plastochrones, as already reported by Bunting \& Drennan (1966).

- The higher rate of extension of subsequent leaves observed in wheat plants (Gallagher 1979) does not exactly counterbalance the greater distance the tip of the lamina has to cover from the growing point, where leaves are initiated, to the point of emergence.

- There is an increase in the period from initiation to emergence for each subsequent leaf.

- That increase is so smali that the differences between subsequent phyllochrones are probably too small to be observed even under controlled conditions.

- The expected decline in the rate of leaf appearance of subsequent leaves provides a good explanation for the differences in the rate of leaf appearance of crops sown at different dates.

Leaf appearance models based on Hypothesis 1 assume phyllochrones to be constant and express them in thermal time (Delecolle \& Gurnade 1980, Kirby \& Perry 1987, Weir et al. 1984), assuming that the differences in the rate of leaf appearance among sowings are related to the rate of change in daylength at crop emergence (Baker et al. 1980).

The use of thermal time for the direct calculation of leaf appearance contradicts the conclusions reached in this paper because it implicitly assumes that phyllochrones are constant and linearly related to temperature.

The assumption made about daylength effects contradicts the results of a number of experimental observations (see Miglietta 1989 for a review), some unpublished scientific experience of M. A. Ford and R. B. Austin (referenced in Kirby et al. 1987), and W. H. Van Dobben and C. T. DeWit (pers. comms.) and the fact that wheat plants become sensitive to daylength only after vernalization requirements are fully met (Rahman 1980, Davidson et al. 1985).

Moreover, the models that estimate leaf appearance rates on the basis of the rate of change in daylength need to be calibrated for different latitudes (Delecolle et al. 1985, Kirby et al. 1987).

The model that is here discussed does not suffer from this drawback and it simplifies, to a large extent, the problem of simulation of leaf appearance under field conditions. 
Hence, provided the final leaf number is known, phasic development and some morphogenetic features of wheat growth can be predicted on the basis of leaf appearance. Shoot apex development is, in fact, coordinated with leaf appearance as well as with the total number of formed leaves (Aitken 1971, Kirby 1988), and both tillering and stem extension processes take place at particular stages of leaf development (Friend et al. 1966, Masle-Maynard \& Sebillotte 1981, Klepper et al. 1984). Thus, the next step forward would be to calculate the final number of leaves initiated by wheat at different latitudes and sowing dates, under different climates. Calculations must be based on a better understanding of the interaction of temperature, photoperiodism and vernalization on wheat development.

Acknowledgements. The author thanks W. H. VanDobben, C. T. DeWit and E. J. M. Kirby for discussion, F. Sabatini for help in field experimenl, and G. Maracchi who made this work possible. Research work was supported by CNR (National Research Council) Italy; Special grant IPRA, Subproject 1, Paper no. 3075.

\section{LITERATURE CITED}

Aitken, Y. (1971). Non-destructive methods for estimation of flower initiation in subterranean clover and cereals. J. Aust. Inst. Agric. Sci. 33: 57-60

Baker, C. K., Gallagher, J. N. (1983). The development of winter wheat in the field 1. Relation between apical development and plant morphology within and between seasons. J. agric. Sci. Camb. 101: 327-335

Baker, C. K., Gallagher, J. N., Montheith, J. L. (1980) Daylength change and leaf apperance in wheat. PI. Cell Environ. 3: 285-287

Benincasa, F., Fasano, G., Materassi, A. (1984). Un sistema automatico per il rilevamento dei parametri meteorologici. Riv. Agron. XVIII (3/4): 220-224

Bunting, A. H., Drennan, D. S. H. (1966). Some aspects of the morphology and physiology of cereals in the vegetative phase. In: Milthorpe, F. L., Ivins, J. D. (eds.) The growth of cereals and grasses. Butterworths, London, p. 20-38.

Davidson, J. L., Christian, K. R., Jones, D. B., Brenmer, P. H. (1985). Responses of wheat to vernalization and photoperiod. Aust. J. agric. Res. 36: 347-359

Delecolle, R., Gurnade, J. C. (1980). Liason entre le development du blè tendre d'hiver: I. Stades de development de l'apex, apparition des feuilles et croissance de la tige. Ann. Amelior. Plant. 30:479-482

Delecolle, R., Couvreur, F., Pluchard, P., Varlet-Grancher, C. (1985). About the leaf-daylength model under French conditions. In: Day, W. Aitken, R. K. (eds.) Wheat growth and modelling. Plenum Press, New York, p. 25-31

Friend, D. J. C., Helson, V. A., Fischer, J. E. (1966). Effect of daylength on the growth of wheat. Can. J. Bot. 45: 117-131

Gallagher, J. N. (1979). Field studies on cereal leaf growth. 1. Initiation and expansion of in relation to temperature and ontogeny. J. exp. Bot. 30: 625-636

Groot, J. J. R. (1987). Simulation of nitrogen balance in a system of winter wheat and soil. Simulation Report CABO-

Editor: G. Esser
TT no. 13, Centre for Agrobiological Research, Department of Theoretical Production Ecology, Agricultural University, Wageningen

Haun, J. R. (1973). Visual quantification of wheat development. Agron. J. 65: 116-119

Hay, R. K. M., Tuncliffe Wilson, G. (1982). Leaf appearance and extension in field grown winter wheat plants: the importance of soil temperature during vegetative growth. J. agric. Sci. Camb. 99: 403-410

Kirby, E. J. M. (1988). Significant stages in cereal development. In: Miglietta, F. (ed.) Models in agriculture and forest research. IPRA-CNR, Roma

Kirby, E. J. M., Appleyard, M., Fellowes, G. (1985). Effect of sowing date and variety on main shoot leaf emergence and number of leaves of barley and wheat. Agronomie 5: $117-126$

Kirby, E. J. M., Appleyard, M. (1986). Cereal development guide. NAC Cereal Unit, Stoneleigh

Kirby E. J. M., Perry M. W. (1987). Leaf emergence rates of wheat in a Mediterranean environment. Aust. J. agric. Res. 38: 455-464

Kiruy, E. J. M., Porter, J. R., Ddy, W., Addn, J. S., Appleyard, M., Ayling, S., Baker, C. K. Beale, P., Belford, R. K., Biscoe, P. V., Chapman, A., Fuller, M. P., Hampson, J., Hay, R. K., Hough, M., Matthews, S., Thompson, W. J., Weir, A. H., Willington, V. B. A., Wood, D. W. (1987). An analysis of primordium initiation in Avalon wheat crops with different sowing dates and at nine sites in England and Scotland. J. agric. Sci. Camb. 109 123:134

Klepper, B., Belford, R. K., Rickman, R. W. (1984). Root and shoot development in winter wheat. Agron. J. 76: 117-122

Malvoisin, P. (1984). Organogenèse et croissance du maitrebrin du blè tendre (Triticum aestivum) du semis a la floraison. I. Relations observèe entre la croissance foliaire et la differentiation des èbauches foliaires ou florales. Agronomie 4: 557-564

Masle-Maynard, J., Sebillotte, M. (1981). Etude de l'heterogeneitè d'un peuplement de blè d'hiver. I. Notion de structure du peuplement. Agronomie 4 (6): 557-564

Miglietta, F. (1989). The effect of photoperiod and temperature on leaf initiation rates in wheat (Triticum spp.). Field Crop Res. 21. 121-130

Miglietta, F., Vazzana, C., LoSavio, N., Mastrorilli, M., Raschi, A. (1987). Calibrazione di un modello di simulazione della crescita del frumento in due ambienti italiani. Riv. Agron 21 (4) suppl.: $240-245$

Rahman, M. S. (1980). Effect of photoperiod and vernalization on the rate of development and spikelet number per ear in 30 varieties of wheat. J. Aust. Inst. Agric. Sci. 46: 68-70

Ross, G. J. S. (1975). Simple non-linear modelling for the general user. Proc. 40th Session Int. Stat. Inst. Warsaw 2: 585-593

Syme, J. R. (1974). Leaf appearance rate and associated characters in some mexican and australian wheats. Aust. J. agric. Res. 25: 1-7

Thomson, W. J. (1985). Growth and development of ten winter wheat cultivars. Tests of agrochemicals and cultivars. Ann. Bot. 106, suppl.: 176-177

Weir, A. H., Bragg, P. L., Porter, J. R., Rayner, J. H. (1984). A winter wheat crop simulation model without water and nutrients limitations. J. agric. Sci. Camb. 102: 371-382

Williams, R. F. Williams, C. N. (1968). Physiology of growth in the wheat plant. IV Effects of day length and light energy level. Aust. J. biol. Sci. 21. 835-854

Manuscript first received: October 16, 1989

Revised version accepted: September 1, 1990 